\title{
Is there any association between leptin levels and bone mineral density in haemophiliac men?
}

\author{
Panagiotis Anagnostis', Sofia Vakalopoulou'2, Maria Charizopoulou³, Eirini Kazantzidou4, \\ Tania Chrysopoulou', Eleni Moka², Alexandra Agapidou², Vassiliki Zournatzi ${ }^{5}$, Vasilia Garipidou²
}

1Department of Endocrinology, Hippokration Hospital, Thessaloniki, Greece

2Division of Haematology, 2nd Propaedeutic Department of Internal Medicine, Aristotle University, Hippokration Hospital, Thessaloniki, Greece

${ }^{3}$ Department of Psychology, School of Philosophy, Aristotle University of Thessaloniki, Greece

4Radiology Department, Hippokration Hospital, Thessaloniki, Greece

${ }^{5} 2^{\text {nd }}$ Department of Obstetrics and Gynaecology, Aristotle University, Hippokration

General Hospital, Thessaloniki, Greece

Submitted: 5 February 2012

Accepted: 1 August 2012

Arch Med Sci 2013; 9, 3: 459-465

DOI: 10.5114/aoms.2013.35341

Copyright $\odot 2013$ Termedia \& Banach

\section{Abstract}

Introduction: Conflicting data exist regarding the role of leptin in bone metabolism. The purpose of the present study was to investigate serum leptin concentrations in male patients with haemophilia A and B, a disease known to be associated with low bone mass.

Material and methods: Eighty-one male patients, aged $45.4 \pm 15$ years, were screened. Bone mineral density (BMD) was measured by dual-energy X-ray absorptiometry (DXA) in lumbar spine (LS), femoral neck (FN) and total hip (TH). Results: Low bone mass was diagnosed in 20 patients (24.7\%). Serum leptin concentrations were strongly associated with body weight $\left(r_{s}=0.457, p=0.0001\right)$ and body mass index (BMI) $\left(r_{s}=0.491, p=0.0001\right)$. In unadjusted analysis leptin was inversely associated with BMD in LS $\left(r_{s}=-0.255, p=0.023\right)$, but not in $\mathrm{FN}$ and $\mathrm{TH}$ ( $r_{s}=-0.205, p=0.068$ and $r_{s}=-0.191, p=0.090$, respectively). However, after adjusting for BMI and body weight, leptin was inversely associated with BMD in FN $\left(F_{1,76}=7.727, p=0.007, \beta=-0.371, \Delta R^{2}=0.089\right)$ and $\mathrm{TH}\left(F_{1,76}=4.533, p=\right.$ $\left.0.036, \beta=-0.290, \Delta R^{2}=0.054\right)$, but not in $\mathrm{LS}\left(F_{1,75}=2.076, p=0.154, \beta=-0.202\right.$, $\Delta R^{2}=0.026$ ). No association was found between age, presence of $\mathrm{HBV}, \mathrm{HCV}$ or HIV infection or alkaline phosphatase and leptin levels.

Conclusions: Our study showed a negative association between circulating leptin levels and bone mass in males, independently of body weight and BMI.

Key words: haemophilia, arthropathy, osteoporosis, osteopenia, leptin.

\section{Introduction}

Haemophilia A and B are congenital bleeding disorders resulting from deficiency in blood coagulation factors VIII (fVIII) and IX (fIX), respectively. They are characterized by intra-articular bleeding which leads to severe arthropathy [1]. Haemophilia A and B have been associated with increased incidence of bone disease (osteopenia or osteoporosis), about $67-86 \%$ in a few studies [2-6]. Prolonged immobilization, avoidance of weight-bearing physical activity during childhood or adolescence, as well as comorbid infections (hepatitis C virus (HCV) and human immunodeficiency virus

\author{
Corresponding author: \\ Panagiotis Anagnostis MD \\ Department of Endocrinology \\ Hippokration Hospital \\ 10 Sarantaporou St \\ 54640, Thessaloniki, Greece \\ Phone: +302310892038 \\ Fax: +302310848453 \\ E-mail: \\ anagnwstis.pan@yahoo.gr
}


(HIV)) are proposed to be the main factors contributing to the pathogenesis of bone disease in haemophilia [2-6].

The protective effect of obesity on bone is well known [7]. Many mechanisms for this interaction have been proposed, such as obesity-related mechanical loading, increased aromatization of estrogens to androgens in adipose tissue, decreased levels of sex hormone binding globulin, and high levels of insulin observed in obese subjects, which may act as a mitogenic factor on osteoblasts [7]. However, all these mechanisms are not completely elucidated, since they have not been confirmed in all studies [8].

A potential candidate providing a more uniform explanation for the link between obesity and osteoporosis may be leptin. Leptin is the product of the ob gene, secreted mainly by white adipose tissue. It constitutes a 14-kDa protein and is strongly correlated with body fat mass, being elevated in obese subjects. Leptin acts at the hypothalamus level, suppressing food intake and stimulating energy expenditure $[9,10]$. Apart from its role in the body's energetic status, leptin may interfere in many endocrine functions (such as secretion from anterior pituitary, ovaries, testis, thyroid and adrenal glands), may act as a growth factor and may also attenuate adipocyte differentiation and lipid accumulation [8]. It exerts these properties through highly specific receptors which have been detected in many tissues, such as haemopoietic precursor cells, placenta and several fetal tissues, adipocytes, lung tissue and jejunum [8].

Furthermore, several lines of evidence support a key role of leptin in bone metabolism. Indeed, in vivo and in vitro studies have shown that leptin promotes the osteoblastic differentiation of bone marrow stromal cells (attenuating reciprocally their differentiation to adipocytes) [11], inhibits the apoptosis of osteoblasts [12] and down-regulates the expression of receptor activator of nuclear factor$\kappa B(R A N K)$ ligand (RANKL), which is a key cytokine in osteoclastogenesis [13]. Moreover, peripheral leptin administration in mice genetically deficient in leptin (ob/ob mice) leads to an increase in total tra- becular and cortical bone mass [14]. However, these experimental data have not been confirmed in human studies, since conflicting results exist. Some authors have reported positive correlations of leptin with bone mineral density (BMD) in cross-sectional studies [15-18], while others have reported an inverse association [19-22] or no association at all [23-28].

The purpose of the present study was to address the association between serum leptin levels and BMD in males.

\section{Material and methods}

\section{Basal clinical and laboratory assessments}

This was a cross-sectional study conducted in the Haemophilia Centre of Northern Greece, in Hippokration Hospital of Thessaloniki, from November 2008 to July 2010. The study was approved by the Local Ethics Committee and all the participants gave their informed consent.

Adult patients $\geq 18$ years of age suffering from mild to severe haemophilia $A$ or $B$, with a regular follow-up in our centre, were included. Severe haemophilia was defined when the levels of fVIII or $\mathrm{fIX}$ were $<1 \%$, moderate when they were $1-5 \%$, and mild disease was defined when their levels were $>5 \%$.

Eighty-one male patients (73 with haemophilia $A$ and 8 with haemophilia B) with a mean age 45.4 \pm 15 years (range 20 -74 years) were screened. Fifteen patients $(18.5 \%)$ were suffering from severe haemophilia, 17 (21\%) from moderate and 49 (60.5\%) from mild disease. Three patients (4\%) were suffering from HBV, 36 (44.4\%) from HCV and 4 (5\%) from HIV infection, on antiviral therapy.

Patients were given a brief questionnaire categorizing their physical activity. More specifically, unrestricted school/work and recreational activities were scored as 5, while inability to participate in recreation due to pain, loss of motion or weakness and requirement of assistance from another person for school/work/self-care was scored as 1 [5] (Table I). Baseline assessment included individual and family history (focusing on conditions or med-

Table I. Activity questionnaire

\begin{tabular}{|lc|}
\hline Self-reported activity level & Score \\
\hline Unrestricted school/work and recreational activities & 5 \\
\hline Full school/work with limited recreational activity levels due to pain, loss of motion or weakness & 4 \\
\hline Limited school/work and recreational activity levels due to pain, loss of motion or weakness & 3 \\
\hline $\begin{array}{l}\text { Limited school/work, recreational activity levels and self-care activity levels due to pain, loss of motion } \\
\text { or weakness }\end{array}$ & 2 \\
\hline $\begin{array}{l}\text { Inability to participate in recreation due to pain, loss of motion or weakness and requirement of assistance } \\
\text { from another person for school/work/self-care }\end{array}$ & 1 \\
\hline
\end{tabular}

US Department of Health and Human Services, Centers for Disease Control and Prevention, Universal Data Collection, Annual Visit Form, November 2002, pg 5. (reference 5) 
ications related to secondary osteoporosis, such as physical activity, current smoking, alcohol use, calcium intake, previous fracture, use of corticosteroids, rheumatoid arthritis, hypogonadism, thyroid disease and history of parental hip fracture or osteoporosis), physical examination and body mass index (BMI) calculation (body weight (kg))/(height $\left.(\mathrm{m})^{2}\right)$.

Morning (8-9 AM) fasting blood samples were obtained from all participants. The patients underwent the following blood tests: fVIII or fIX activity levels and inhibitor titres, basal biochemical examination (including serum creatinine, total calcium, albumin, phosphorus, alkaline phosphatase (ALP), aspartate transaminase, alanine transaminase, total (direct/indirect) bilirubin and prothrombin time) and serological screening for hepatitis B virus (HBV), $\mathrm{HCV}$ and HIV, with viral loads if screened positive. Serum was immediately centrifuged and stored at $-30^{\circ} \mathrm{C}$ for the measurement of leptin, which was performed by enzyme-linked immunosorbent assay (ELISA), (Mercodia, Uppsala, Sweden), according to the manufacturer's instructions.

\section{Assessment of haemophilic arthropathy}

Plain radiographs of both knees and ankles, as well as any other joint affected by haemophilic arthropathy, were obtained by all patients and were examined by 2 expert radiologists. Two different score systems were used for this purpose: the Pettersson score (normal joints are scored as 0 and the highest score possible for a joint is 13) [29] and the Arnold-Hilgartner classification system (normal joint score is 0 and the highest is 5) [30] (Tables II and III).

\section{Bone densitometry}

Bone mineral density was assessed by dualenergy X-ray absorptiometry (DXA), which is the most widely used method [31]. DXA of lumbar spine (LS) (L1-L4), left femoral neck (FN) and total hip (TH) were performed by a single experienced operator. Right FN was chosen if the left one was affected by severe arthropathy or when arthroplasty had been performed. The areal BMD in grams per square centimetre $\left(\mathrm{g} / \mathrm{cm}^{2}\right)$ of the anteroposterior projections of DXA was measured by a Challenger Envision osteodensitometer (Diagnostic Medical System, Montpellier, France) in Hippokration Hospital of Thessaloniki. For patients $>50$ years of age, $T$-score values between -1 and -2.5 standard deviations (SD) were defined as osteopenia, while values below -2.5 SD were defined as osteoporosis, according to the criteria for the definition of osteoporosis in males by the International Society of Clinical Densitometry and the World Health Organization $(\mathrm{WHO})$ [32]. For patients $<50$ years, a Z-score of
Table II. Pettersson staging system for haemophilic arthropathy

\begin{tabular}{|c|c|}
\hline Finding & Score \\
\hline \multicolumn{2}{|l|}{ Osteoporosis } \\
\hline Absent & 0 \\
\hline Present & 1 \\
\hline \multicolumn{2}{|c|}{ Enlargement of epiphysis } \\
\hline Absent & 0 \\
\hline Present & 1 \\
\hline \multicolumn{2}{|c|}{ Irregularity of subchondral surface } \\
\hline Absent & 0 \\
\hline Slight & 1 \\
\hline Pronounced & 2 \\
\hline \multicolumn{2}{|c|}{ Narrowing of joint space } \\
\hline Absent & 0 \\
\hline$<50 \%$ & 1 \\
\hline$>50 \%$ & 2 \\
\hline \multicolumn{2}{|c|}{ Erosions at joint margins } \\
\hline Absent & 0 \\
\hline Present & 1 \\
\hline \multicolumn{2}{|c|}{ Subchondral cyst formation } \\
\hline Absent & 0 \\
\hline 1 cyst & 1 \\
\hline$>1$ cysts & 2 \\
\hline \multicolumn{2}{|c|}{ Incongruence between joint surfaces } \\
\hline Absent & 0 \\
\hline Slight & 1 \\
\hline Pronounced & 2 \\
\hline \multicolumn{2}{|l|}{ Deformity } \\
\hline Absent & 0 \\
\hline Slight & 1 \\
\hline Pronounced & 2 \\
\hline
\end{tabular}

$<-2$ SD or lower was defined as "below the expected range for age", according to the previous criteria [32]. Thus, decreased BMD was defined either as osteopenia/osteoporosis for patients $>50$ years or as a Z-score $<-2$ for those younger than 50 years of age.

Bone mineral density was also measured in agematched healthy males without a reported cause or severe risk factor for secondary osteoporosis, who served as controls. They were from the same geographical region as the patients, in order to obtain more accurate results. They gave their informed consent and their screening was approved by the ethical committee. They were not infected by HBV, HCV or HIV. There was no restriction in their physical activity. 
Table III. Arnold-Hilgartner classification system

\begin{tabular}{|lc|}
\hline Findings & Stage \\
\hline Normal joint & 0 \\
\hline No skeletal abnormalities, soft tissue swelling present & 1 \\
\hline Osteoporosis and overgrowth of epiphysis; no erosions; no narrowing of cartilage space & 2 \\
\hline $\begin{array}{l}\text { Early subchonrdal bone cysts; squaring of the patella; intercondylar notch of distal femur or humerus widened; } \\
\text { cartilage space remains preserved }\end{array}$ & 3 \\
\hline Findings of stage 3 more advanced; cartilage space narrowed & 4 \\
\hline $\begin{array}{l}\text { Fibrous joint contracture; loss of joint cartilage space; marked enlargement of the epiphysis and substantial } \\
\text { disorganization of the joint }\end{array}$ & 5 \\
\hline
\end{tabular}

\section{Statistical analysis}

Statistical analyses were performed with the Statistical Package for the Social Sciences (SPSS) for Windows (version 17.0). All statistical tests were two-tailed; $p$-values $<0.05$ were considered statistically significant. Based on the distribution of data (checked by Kolmogorov-Smirnov test and ShapiroWilk test) non-parametric statistics were used. Descriptive statistics of demographic and clinical data are represented as frequencies, percentages, means, SDs and minimum and maximum values.

Preliminary analyses examined the associations between bone disease and age, BMI, ALP, number of affected joints, degree of physical activity, severity of haemophilia or haemophilic arthropathy scores and HBV/HCV/HIV infection, as well as between leptin and presence of HBV/HCV/HIV infection using $\chi^{2}$ and Mann-Whitney $U$-test, as appropriate. Spearman $r_{s}$ correlation was conducted in order to indicate the association between leptin and BMD in 3 sites, body weight, BMI, age, ALP or severity of arthropathy assessed by the Pettersson score and Arnold-Hilgartner classification system. Finally a series of hierarchical multiple regressions was used to test the predictability of various variables (severity of haemophilia, physical activity, severity of arthropathy) for BMD after controlling for age, BMI, risk factors, number of affected joints and $\mathrm{HBV} / \mathrm{HCV} / \mathrm{HIV}$.

\section{Results}

The patients' characteristics are presented in Table IV. Low BMD was diagnosed in 20 patients with haemophilia (24.7\%), which was significantly higher than its prevalence in controls (20\%) ( $p=$ 0.001 ). With respect to the severity of haemophilia, decreased BMD was observed in $27 \%$ of those with severe, in $41 \%$ of those with moderate and in $18 \%$ of those with mild disease. With respect to virus infections, none of the HBV, 10 (28\%) of the $\mathrm{HCV}$ and 2 (50\%) of the HIV patients manifested decreased BMD.

The mean leptin levels in the whole cohort were $9.26 \pm 9.89 \mathrm{ng} / \mathrm{ml}$ (range 0.05-51.97). The mean lep-

Table IV. Clinical and biochemical characteristics of haemophiliac patients

\begin{tabular}{|c|c|c|c|}
\hline Variable & Mean \pm SD & Minimum & Maximum \\
\hline No. of subjects tested & 81 & & \\
\hline Age [years] & $45.37 \pm 15.07$ & 20 & 74 \\
\hline Height $[\mathrm{cm}]$ & $175.32 \pm 7.47$ & 164 & 200 \\
\hline Body weight $[\mathrm{kg}]$ & $82.49 \pm 13.70$ & 56 & 130 \\
\hline BMI $\left[\mathrm{kg} / \mathrm{m}^{2}\right]$ & $26.82 \pm 4.30$ & 18.82 & 44.28 \\
\hline BMD lumbar spine $\left[\mathrm{g} / \mathrm{cm}^{2}\right]$ & $1.153 \pm 0.166$ & 0.708 & 1.626 \\
\hline BMD femoral neck $\left[\mathrm{g} / \mathrm{cm}^{2}\right]$ & $0.944 \pm 0.159$ & 0.560 & 1.368 \\
\hline BMD total hip $\left[\mathrm{g} / \mathrm{cm}^{2}\right]$ & $0.933 \pm 0.160$ & 0.567 & 1.339 \\
\hline Number of joints affected & $2.79 \pm 2.16$ & 0 & 8 \\
\hline Alkaline phospatase [IU/I] & $73.41 \pm 18.41$ & 44 & 148 \\
\hline Serum leptin in total patients $[\mathrm{ng} / \mathrm{ml}]$ & $9.27 \pm 9.90$ & 0.05 & 51.97 \\
\hline Serum leptin in subjects normal BMD [ng/ml] $(n=61)$ & $8.16 \pm 9.32$ & 0.05 & 51.97 \\
\hline Serum leptin in subjects with bone disease $[\mathrm{ng} / \mathrm{ml}](n=20)$ & $12.61 \pm 11.05$ & 3.15 & 44.72 \\
\hline
\end{tabular}

$B M I$ - body mass index, $B M D$ - bone mineral density 
tin concentration in patients with low bone mass $(n=20)$ was $12.61 \pm 11.05 \mathrm{ng} / \mathrm{ml}$ (range 3.15-44.72) and in patients with normal BMD $(n=61)$ was 8.16 $\pm 9.32 \mathrm{ng} / \mathrm{ml}$ (range 0.05-51.97). Leptin levels were strongly correlated with body weight $\left(r_{s}=0.454\right.$, $p=0.0001)$ and BMI $\left(r_{s}=0.491, p=0.0001\right)$. In unadjusted analysis, leptin was inversely associated with BMD in LS $\left(r_{s}=-0.255, p=0.023\right)$, but not with BMD in FN and $\mathrm{TH}\left(r_{s}=-0.205, p=0.068\right.$ and $r_{s}=-0.191, p=0.090$, respectively). However, after adjusting for $\mathrm{BMI}$ and body weight, leptin was no more related to BMD in $\mathrm{LS}\left(F_{1,75}=2.076, p=0.154\right.$, $\left.\beta=-0.202, \Delta R^{2}=0.026\right)$, but was negatively associated with BMD in FN $\left(F_{1,76}=7.727, p=0.007\right.$, $\left.\beta=-0.371, \Delta R^{2}=0.089\right)$ and $\mathrm{TH}\left(F_{1,76}=4.533, p=\right.$ $\left.0.036, \beta=-0.290, \Delta R^{2}=0.054\right)$.

No association was found between age $\left(r_{s}=\right.$ 0.008, $p=0.946)$, presence of HBV, HCV or HIV infection ( $p=0.094, p=0.587, p=0.783$, respectively) or ALP (as a marker of bone formation) and leptin levels $\left(r_{s}=0.147, p=0.210\right)$. Furthermore, no association was also found between the severity of arthropathy (assessed by Pettersson score for knees and ankles: $r_{s}=0.120, p=0.334, r_{s}=0.110, p=$ 0.375 , respectively and with Arnold-Hilgartner classification system: $r_{s}=0.092, p=0.461, r_{s}=0.226$, $p=0.066$, respectively) and leptin levels.

Bone mineral density as a nominal variable (defined as normal or low) was positively associated with the level of physical activity $\left(\chi^{2}(3)=55.64\right.$, $p=0.001)$ and inversely with the severity of haemophilia $\left(\chi^{2}(2)=26.96, p=0.001\right)$. No association was found between BMD and the haemophilic arthropathy scores for knees and ankles (with Pettersson score for knees and ankles: $U=324, p=$ 0.317 and $U=349, p=0.373$ respectively, and with Arnold-Hilgartner classification system: $U=323$, $p=0.299$ and $U=325, p=0.206$, respectively). In unadjusted analyses, age $(p=0.558), \mathrm{BMI}(p=$ $0.818)$, number of affected joints $(p=0.55)$ and ALP levels $(p=0.326)$ were not associated with BMD. In terms of viral infection, BMD was significantly associated with HIV $\left(\chi^{2}(1)=64.8, p=0.0001\right)$, but not with HCV infection $\left(\chi^{2}(1)=1.25, p=0.264\right)$. However, the number of patients with HIV infection was too low for safe conclusions. Finally, after controlling for age, BMI, risk factors for osteoporosis (smoking, alcohol, previous fracture, calcium intake, family history of osteoporosis), number of affected joints, HCV, and HIV in hierarchical multiple regressions, only the degree of physical activity $\left(F_{1,64}=\right.$ 8.005, $\left.p=0.006, \beta=-0.364, \Delta R^{2}=0.101\right)$ appeared to predict $\mathrm{BMD}$.

\section{Discussion}

Our study demonstrated a negative association between leptin and BMD, and, in particular, at the femoral neck and total hip sites, independently of body weight and BMI. Few studies have evaluated this association in men. Apart from a positive correlation in the elderly population (68-75 years of age) [17], an inverse association has also been shown in middle aged subjects (47-52 years of age) after adjustment for body weight $[19,20]$. Positive [15-18], negative [21, 22] or neutral [23-28] association between BMD and leptin has been observed in women, irrespectively of BMI and menopausal status. Our study's findings are in accordance with those of the largest study conducted so far, which evaluated the association between BMD and leptin, included 5815 adults from the Third U.S. National Health and Nutrition Examination Survey (NHANES III; 1988-1994) and involved both men and premenopausal and postmenopausal women. Despite a positive correlation between leptin and BMD in unadjusted analyses in all groups, after adjusting for BMI, an inverse relationship between leptin and BMD emerged in both men and premenopausal women, while no association was found in postmenopausal ones. The inverse association was more evident for men younger than 60 years old [33].

The reasons for these conflicting results from human studies regarding the association between leptin and BMD are not clear. Perhaps the different size of population, age and ethnicity factors may play a role. Moreover, an indirect effect of leptin on bone mass through testosterone has also been proposed [33]. It is well known that testosterone increases BMD in men [34] and leptin seems to correlate negatively with total and bioavailable testosterone levels [35]. On the other hand, a positive association between leptin and oestrogen has also been described [35]. Apart from women, oestrogen seems to be an important predictor of bone mass in men since it correlates positively with BMD [36]. In a recent case-cohort study in older men (> 65 years), serum oestradiol levels correlated inversely with fracture risk in contrast to testosterone levels [37].

Although most experimental studies indicate a beneficial role of leptin in bone metabolism, there are some studies yielding contradictory results. In particular, some investigators have observed higher trabecular bone mass in ob/ob mice compared with their wild-type littermates and intracerebroventricular administration of leptin in these mice normalizes bone mass [38]. A central anti-osteogenic action of leptin via the sympathetic nervous system has also been described [38]. Remarkably, it seems that the route of leptin administration may also play a role, since peripheral administration induces osteoblastic activity both in mice [14] and humans [39]. A more unifying model suggests that leptin may have a dual action by exerting stimulatory peripheral effects on immature bone cells early in life, thus increasing bone mass, and later in 
life it displays a central inhibitory effect on bone turnover, counterbalancing its former actions. On the onset of obesity and concomitant leptin resistance, leptin cannot overcome the blood-brain barrier and, thus, its serum levels increase and its peripheral anabolic actions predominate [8].

Emerging evidence also suggests a potential role of leptin in the pathogenesis of osteoarthritis (OA). Notably, leptin has been detected in synovial fluid from joints affected by OA, with its levels correlating positively with $\mathrm{BMI}$ and being similar or higher than those measured in serum [40]. Furthermore, marked expression of leptin receptors has been observed in OA cartilage compared with normal one, being also related to the grade of cartilage destruction [40, 41]. Interestingly, intra-articular administration of leptin in rats seems to stimulate chondrocyte activity and expression of several growth factors such as insulin-like growth factor 1 and transforming growth factor- $\beta$ [40]. Leptin has also been reported to increase proliferation and proteoglycan and collagen synthesis in human chondrocytes [41]. However, its role in OA seems to be more complex, since there is also evidence for a catabolic action on cartilage metabolism [42]. In addition, leptin may act as a proinflammatory agent since it enhances the synthesis of several inflammatory factors implicated in the pathogenesis of $\mathrm{OA}$, such as nitric oxide, prostaglandin $\mathrm{E} 2$, interleukin-6 and interleukin 8, thus providing a more plausible mechanism for the pathogenesis of obesity-related OA [43]. Of note, a positive association between serum leptin and hip joint-space narrowing has been reported in older adults with OA [44]. However, we failed to show any association between leptin levels and the degree of haemophiliac arthropathy, assessed by the Pettersson score and the Arnold-Hilgartner classification system.

We found an increased incidence of bone disease (either as osteopenia or osteoporosis) in haemophiliac patients of northern Greece, although lower than previously reported [2-6]. This difference with previous studies may be due to the fact that they included mainly patients with severe haemophilia (reporting a prevalence of > 67\%) [2-6]. Another significant reason for the discordant results is the fact that in these studies $T$-scores were used in all patients irrespectively of their age. Based on the criteria for the definition of osteoporosis in males by the International Society of Clinical Densitometry and the WHO, we used T-scores for patients older than 50 years and Z-scores for those younger than 50 [32]. By using $T$-scores, the prevalence of bone disease would have been about $50 \%$. The severity of haemophilia and the degree of physical activity were the only factors associated with BMD, which is also in line with these studies [2-6], although after adjusting for possible confounders only the degree of physical activity remained significantly correlated with BMD. However, we did not find any correlation between BMD and age, BMI and HCV-HIV infections, in contrast to most studies $[2,3,5,6]$, although in a recent meta-analysis, low BMD was not associated with BMI and HCV [45].

In conclusion, the present study demonstrated an inverse association between leptin levels and $B M D$ in femoral neck and total hip in male patients with haemophilia A and B, a cohort of patients with increased prevalence of bone disease. This association was independent of body weight and BMI. Furthermore, although intriguing data exist with respect to the role of this hormone in the pathogenesis of OA, we failed to show any association between this hormone and the degree of arthropathy. It is conceivable that the link between fat and bone mass is quite complex and still large, welldesigned human studies are warranted to better clarify this interaction.

\section{References}

1. Eshghi P, Mahdavi-Mazdeh M, Karimi M, Aghighi M. Haemophilia in the developing countries: the Iranian experience. Arch Med Sci 2010; 6: 83-9.

2. Gallacher SJ, Deighan C, Wallace AM, et al. Association of severe haemophilia A with osteoporosis: a densitometric and biochemical study. Q J Med 1994; 87: 181-6.

3. Wallny TA, Scholz DT, Oldenburg J, et al. Osteoporosis in haemophilia - an underestimated comorbidity? Haemophilia 2007; 13: 79-84.

4. Nair AP, Jijina F, Ghosh K, Madkaikar M, Shrikhande M, Nema M. Osteoporosis in young haemophiliacs from western India. Am J Hematol 2007; 82: 453-7.

5. Gerstner G, Damiano ML, Tom A, Schultz W, Recht M, Stopeck AT. Prevalence and risk factors associated with decreased bone mineral density in patients with haemophilia. Haemophilia 2009; 15: 559-65.

6. Katsarou O, Terpos E, Chatzismalis P, et al. Increased bone resorption is implicated in the pathogenesis of bone loss in hemophiliacs: correlations with hemophilic arthropathy and HIV infection. Ann Hematol 2010; 89: 67-74.

7. Reid IR. Relationships between fat and bone. Osteoporos Int 2008; 19: 595-606.

8. Thomas T. The complex effects of leptin on bone metabolism through multiple pathways. Curr Opin Pharmacol 2004; 4: 295-300.

9. Considine RV, Sinha MK, Heiman ML, et al. Serum immunoreactive-leptin concentrations in normal-weight and obese humans. N Engl J Med 1996; 334: 292-5.

10. Athyros VG, Tziomalos K, Karagiannis A, Anagnostis P, Mikhailidis DP. Should adipokines be considered in the choice of the treatment of obesity-related health problems? Curr Drug Targets 2010; 11: 122-35.

11. Thomas T, Gori F, Khosla S, Jensen MD, Burguera B, Riggs BL Leptin acts on human marrow stromal cells to enhance differentiation to osteoblasts and to inhibit differentiation to adipocytes. Endocrinology 1999; 140: 1630-8.

12. Gordeladze JO, Drevon CA, Syversen U, Reseland JE. Leptin stimulates human osteoblastic cell proliferation, de novo collagen synthesis, and mineralization: Impact on differentiation markers, apoptosis, and osteoclastic signaling. J Cell Biochem 2002; 85: 825-36. 
13. Burguera B, Hofbauer LC, Thomas T, et al. Leptin reduces ovariectomy-induced bone loss in rats. Endocrinology 2001; 142: 3546-53.

14. Steppan CM, Crawford DT, Chidsey-Frink KL, Ke H, Swick AG. Leptin is a potent stimulator of bone growth in ob/ob mice. Regul Pept 2000; 92: 73-8.

15. Yamauchi M, Sugimoto T, Yamaguchi T, et al. Plasma leptin concentrations are associated with bone mineral density and the presence of vertebral fractures in postmenopausal women. Clin Endocrinol (Oxf) 2001; 55: 341-7.

16. Roux C, Arabi A, Porcher R, Garnero P. Serum leptin as a determinant of bone resorption in healthy postmenopausal women. Bone 2003; 33: 847-52.

17. Zoico E, Zamboni M, Adami S, et al. Relationship between leptin levels and bone mineral density in the elderly. Clin Endocrinol (Oxf) 2003; 59: 97-103.

18. Pasco JA, Henry MJ, Kotowicz MA, et al. Serum leptin levels are associated with bone mass in nonobese women. J Clin Endocrinol Metab 2001; 86: 1884-7.

19. Sato M, Takeda N, Sarui H, et al. Association between serum leptin concentrations and bone mineral density, and biochemical markers of bone turnover in adult men. J Clin Endocrinol Metab 2001; 86: 5273-6.

20. Morberg CM, Tetens I, Black E, et al. Leptin and bone mineral density: a cross-sectional study in obese and nonobese men. J Clin Endocrinol Metab 2003; 88: 5795-800.

21. Ushiroyama T, Ikeda A, Hosotani T, Higashiyama T, Ueki M. Inverse correlation between serum leptin concentration and vertebral bone density in postmenopausal women. Gynecol Endocrinol 2003; 17: 31-6.

22. Blum M, Harris SS, Must A, et al. Leptin, body composition and bone mineral density in premenopausal women. Calcif Tissue Int 2003; 73: 27-32.

23. Goulding A, Taylor RW. Plasma leptin values in relation to bone mass and density and to dynamic biochemical markers of bone resorption and formation in postmenopausal women. Calcif Tissue Int 1998; 63: 456-8.

24. Martini G, Valenti R, Giovani S, Franci B, Campagna S, Nuti R. Influence of insulin-like growth factor-1 and leptin on bone mass in healthy postmenopausal women. Bone 2001; 28: 113-7.

25. Odabași E, Ozata M, Turan M, et al. Plasma leptin concentrations in postmenopausal women with osteoporosis. Eur J Endocrinol 2000; 142: 170-3.

26. Rauch F, Blum WF, Klein K, Allolio B, Schönau E. Does leptin have an effect on bone in adult women? Calcif Tissue Int 1998; 63: 453-5.

27. Iwamoto I, Douchi T, Kosha S, Murakami M, Fujino T, Nagata Y. Relationships between serum leptin level and regional bone mineral density, bone metabolic markers in healthy women. Acta Obstet Gynecol Scand 2000; 79: 1060-4.

28. Hadji P, Bock K, Gotschalk M, et al. The influence of serum leptin concentration on bone mass assessed by quantitative ultrasonometry in pre and postmenopausal women. Maturitas 2003; 44: 141-8.

29. Pettersson H, Ahlberg A, Nilsson IM. A radiologic classification of hemophilic arthropathy. Clin Orthop Relat Res 1980; 149: 153-9.

30. Ng WH, Chu WC, Shing MK, et al. Role of imaging in management of hemophilic patients. AJR Am J Roentgenol 2005; 184: 1619-23.

31. Haugeberg G. Imaging of metabolic bone diseases. Best Pract Res Clin Rheumatol 2008; 22: 1127-39.

32. Baim S, Binkley N, Bilezikian JP, et al. Official Positions of the International Society for Clinical Densitometry and executive summary of the 2007 ISCD Position Development Conference. J Clin Densitom 2008; 11: 75-91.

33. Ruhl CE, Everhart JE. Relationship of serum leptin concentration with bone mineral density in the United States population. J Bone Miner Res 2002; 17: 1896-903.

34. Morley JE, Perry HM III. Androgen deficiency in aging men: Role of testosterone replacement therapy. I Lab Clin Med 2000; 135: 370-8.

35. Thomas T, Burguera B, Melton LJ III, et al. Relationship of serum leptin levels with body composition and sex steroid and insulin levels in men and women. Metabolism 2000; 49: 1278-84.

36. Khosla S, Melton LJ III, Atkinson EJ, O'Fallon WM, Klee GG, Riggs BL. Relationship of serum sex steroid levels and bone turnover markers with bone mineral density in men and women: a key role for bioavailable estrogen. J Clin Endocrinol Metab 1998; 83: 2266-74.

37. LeBlanc ES, Nielson CM, Marshall LM, et al.; Osteoporotic Fractures in Men Study Group. The effects of serum testosterone, estradiol, and sex hormone binding globulin levels on fracture risk in older men. J Clin Endocrinol Metab 2009; 94: 3337-46.

38. Ducy P, Amling M, Takeda S, et al. Leptin inhibits bone formation through a hypothalamic relay: a central control of bone mass. Cell 2000; 100: 197-207.

39. Faroogi IS, Jebb SA, Langmack $G$, et al. Effects of recombinant leptin therapy in a child with congenital leptin deficiency. N Engl J Med 1999; 341: 879-84.

40. Dumond H, Presle N, Terlain B, et al. Evidence for a key role of leptin in osteoarthritis. Arthritis Rheum 2003; 48: 3118-29.

41. Simopoulou T, Malizos KN, Iliopoulos D, et al. Differential expression of leptin and leptin's receptor isoform (Ob-Rb) mRNA between advanced and minimally affected osteoarthritic cartilage; effect on cartilage metabolism. Osteoarthritis Cartilage 2007; 15: 872-83.

42. Bao JP, Chen WP, Feng J, Hu PF, Shi ZL, Wu LD. Leptin plays a catabolic role on articular cartilage. Mol Biol Rep 2010; 37: 3265-72.

43. Vuolteenaho K, Koskinen A, Kukkonen M, et al. Leptin enhances synthesis of proinflammatory mediators in human osteoarthritic cartilage: mediator role of NO in leptin-induced PGE2, IL-6, and IL-8 production. Mediators Inflamm 2009; 2009: 345838.

44. Stannus OP, Jones G, Quinn SJ, Cicuttini FM, Dore D, Ding C. The association between leptin, interleukin- 6 , and hip radiographic osteoarthritis in older people: a crosssectional study. Arthritis Res Ther 2010; 12: R95.

45. Iorio A, Fabbriciani G, Marcucci M, Brozzetti M, Filipponi P. Bone mineral density in haemophilia patients. A metaanalysis. Thromb Haemost 2010; 103: 596-603. 